\title{
Investigating Foreign Language Reading Anxiety Among Yemeni International Students in Malaysian Universities
}

\author{
Norizan Abdul Razak ${ }^{1}$, Amr Abdullatif Yassin ${ }^{1,2} \&$ Marwan Saeed Saif Moqbel $^{2}$ \\ ${ }^{1}$ Faculty of Social Sciences and Humanities, Universiti Kebangsaan Malaysia, Bangi, Selangor, Malaysia \\ ${ }^{2}$ Centre of Languages and Translation, Ibb University, Ibb, Yemen \\ Correspondence: Amr Abdullatif Yassin, Centre of Languages and Translation, Ibb University, Yemen. E-mail: \\ amryassin84@gmail.com
}

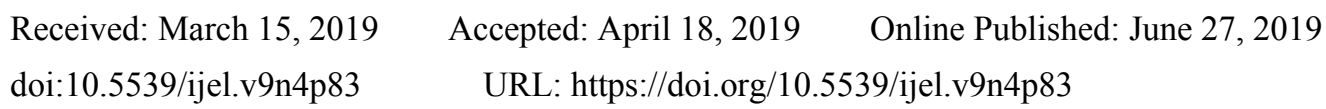

\begin{abstract}
The study aimed at identifying the level and sources of foreign language reading anxiety among Yemeni students in Malaysian universities. Besides, it aimed at finding out whether there are statistically significant differences in the means of responses of Yemeni students in Malaysian universities according to the variable 'Level of study' (Bachelor's, Master's and $\mathrm{PhD}$ ). The study is quantitative as it used Foreign Language Reading Anxiety Scale (FLRAS) to answer the study questions. FLRAS was distributed to general groups of Yemeni students in Malaysia in the form of an online survey. The number of participants who responded to the survey is 100 Yemen students who are preparing their bachelor's, master's and $\mathrm{PhD}$ degrees in different majors in Malaysia. The results of the study showed that the level of foreign language reading anxiety among Yemeni students in Malaysian universities is of moderate level across the three groups. More importantly, the result of the analysis showed that there are no statistically significant differences in the means of responses of Yemeni students in Malaysian universities according to the variable 'Level of study' (Bachelor's, Master's and PhD). The findings of the study highlighted an important point in the investigation of foreign language reading anxiety which is the environment. Thus, studies on intercultural learning stated that the host culture is a source of learning anxiety; however, the moderate level of reading anxiety across the three groups in this study might be attributed to the fact that the medium of instruction and reading materials in Malaysian universities are in English language. Therefore, this finding makes a crystal-clear difference between reading anxiety and general intercultural learning anxiety in the host cultures where English is the medium of instruction. Students, instructors and researchers in this area might benefit from the findings of this study.
\end{abstract}

Keywords: foreign language reading anxiety, reading anxiety sources, Yemeni university students, EFL, Malaysian universities

\section{Introduction}

One of the most influential factors in the process of learning is anxiety as it might have a debilitating effect on the learners (Olivares-Cuhat, 2010; Liu \& Huang, 2011; Wei \& Yodkamlue, 2012; Zhang \& Zhong, 2012; Sahranavard \& Hassan, 2015; Akkakoson, 2016; Yassin \& Razak, 2018). Although students need reading more than the other skills during their study, reading anxiety was given a little concern at the beginning, and this is may be due the fact that reading does not require interaction with the others (Joo \& Damron, 2015). Some students feel anxious when they read any text in front of others or when they read inside the classroom or at home. Due to psychological factors, a student of a foreign language may feel anxious when reading in the public or in front of the other students. A student of a foreign language may even feel anxious when reading a text privately inside the test hall or inside the class or at home as there are different reasons for the sense of anxiety and one of them is unfamiliar features of the text (Saito, Garza, \& Horwitz, 1999). In other words, when students encounter a text with unfamiliar script or writing system, they may feel confused as they might not be able to understand the text and, therefore, the level of their anxiety get increased, which can affect the process and product of reading significantly. Moreover, texts with unfamiliar cultural aspects might cause anxiety for the students as they might not be able to decipher the cultural aspects of the target language (Satio et al., 1999). With these assumptions in mind, one can easily feel the strong need for further research in this area especially among students in the host environment where the medium of instruction is English. 
The number of students who study English as a second or foreign language is increasing day after day due to the importance of English in the modern era as it has become the main language of instruction in most of the universities worldwide. One of the psychological problems that might negatively affect students in reading is anxiety (Horwitz, Horwitz, \& Cope, 1986). According to Alderson (2005), the factors that might lead to reading anxiety can be classified into two categories. The first one is reader variables which are the internal factors that cause anxiety, and the second one is text variables or the external factors that might lead to anxiety. However, there might be specific problems in the process of reading in the target language, especially when the writing system of the target language differs from the writing system of the mother tongue like Arabic. Al-Shboul, Ahmad, Nordin and Rahman (2013) stated that the reading circuitry process of Arabic speakers differs from those whose mother tongue has the same orthography of English language, which might make reading in English more difficult for Arabic speakers, and hence a source of reading anxiety.

Moreover, one of the negative effects of language anxiety, like reading anxiety, is that it has a negative effect on language learning (Razak, Yassin, \& Maasum 2017; Ali \& Fei, 2016). According to Saito et al. (1999), high level of reading anxiety may lead students not to be successful in learning a second or foreign language. However, at university, reading is an important skill as the students depend too much on reading even if they are studying majors other than English language. High level of reading anxiety might prevent students from getting the required amount of knowledge from the text, which might lead to a negative influence on the academic achievement of students. Moreover, anxiety might lead to the failure of the students in the course or bestow them with a negative attitude towards reading and learning in general (Yassin \& Razak, 2017).

The number of Yemeni students in Malaysia is high in comparison to the other nationalities. Most of the majors in the Malaysia higher education institutes use English as a medium of instruction. Accordingly, reading in English language is a must for international students in the Malaysian universities who might also fail to achieve their aims if they cannot read without having any tension during the process of study. More importantly, most of the studies that have investigated reading anxiety among Arab students focused on the students who are majored in English language in their home countries, and investigating reading anxiety among Arab learners in general has not given enough attention from the side of researchers (Al-Shboul et al., 2013), especially among the students who are studying in a host country where the language of instruction is English language.

Hence, this study focused on Yemeni EFL learners who are studying different majors in Malaysian universities. Generally, there is a need to investigate the issue of reading anxiety among Yemeni university students in Malaysia in all the levels to get a better understanding for the effect of the host environment on reading anxiety. An important point is that, most of Yemeni students came for Arabic background, and most postgraduate students have prepared their previous studies in Yemen where the medium of instruction is Arabic language. Therefore, investigating reading anxiety among Yemeni students will give a clear picture for the effect of the host environment on reading anxiety, because the students have to study and read in English language.

\section{Literature Review}

Language anxiety is considered as an important factor in foreign language learning process (Horwitz et al., 1986). It has been studied from different perspectives and with focusing on different factors. The main focus of previous studies was on speaking skill since it is the skill which learners need most of the time as it is the medium of communication. Investigating the other skills was neglected at the beginning. Recently, reading anxiety has received a lot of concern. Studies investigated reading anxiety focused on the relationship between the general anxiety which students experience inside the classroom and the anxiety which students experience during the process of reading.

Anxiety was considered as a feeling of restlessness and it was not a part of language learning until the work of Horwitz et al. (1986) who defined language anxiety as a feeling associated with language learning, and it is a distinguished phenomenon. Foreign language anxiety is a unique feeling of language learning and it is related to feelings, perceptions and beliefs of students concerning language learning, especially inside the classroom (Horwitz et al., 1986).

Reading anxiety is considered by many researchers such as Saito et al. (1999), Sellers (2000), Wu (2011), and Subasi (2014) as a distinct phenomenon from the other types of anxiety. What makes reading anxiety distinct is that students encounter written materials in all the subjects regardless their major which makes reading the center of the process of learning (Grabe \& Stoller, 2001). During the process of reading, students need to decode words. Besides, there are many other elements such as the cultural elements and the unfamiliar words that cause high level of reading anxiety (Genç, 2016). 
Saito et al. (1999) — who administered (FLCAS) and (FLRAS) to English university students of three languages: Japanese, French, and Russian - showed that reading anxiety is a distinct skill, yet it is related to the general foreign language anxiety. Satio et al. (1999) mentioned two factors that might lead to foreign language reading anxiety. The first one is the unfamiliar script besides writing system as those who are familiar with the script or the writing system of the target language are less anxious than those who are not familiar and vice versa. The second one is the unfamiliar culture; students of foreign language might experience anxiety when they are not able to understand the cultural aspects that stand behind the words. The study revealed that there is a relationship between foreign language classroom anxiety and foreign language reading anxiety. That is, students who have anxiety in a foreign language tend to have anxiety in foreign language reading and vice versa. The study also revealed that the two scales shared $41 \%$ of the variance and were different in $59 \%$ of the variance, which is considered as an evidence that there is a difference between foreign language reading anxiety and foreign language anxiety in general. In addition, the same result is obtained by Sellers (2000) who investigated the relationship between foreign language anxiety and foreign language reading anxiety among 89 students of Spanish language. The study concluded that foreign language anxiety is different from foreign language reading anxiety. Moreover, the same result is obtained by $\mathrm{Wu}$ (2011) who investigated the same issue among 91 Taiwanese students. Similarly, the study concluded that foreign language anxiety is different from the specific skill of language learning, namely reading.

In the same vein, Kuru-Gonen carried out three consecutive studies: 2005, 2007, and 2009. He investigated the relationship between language learning anxiety in general and reading anxiety as a specific skill. The researcher used both FLCAS and FLRAS to 255 students of English language in Turkey.

Kuru-Gonen tried to identify the relationship between foreign language classroom anxiety and foreign language reading anxiety. In the three studies, Kuru-Gonen applied (FLCAS) and (FLRAS) to (225) Turkish students of English as a foreign language. The result showed that the two scales were different in about $80 \%$ of variance and both scales shared only $20 \%$ of variance, which indicates that reading anxiety differs from the general feeling of language learning anxiety.

The factors and sources of foreign language reading anxiety was investigated by some research. Rajaba, Zakariab, Rahmanc, Hosnid and Hassanie (2012) aimed at identifying the level of reading anxiety in Teknology Malaysia University. The participants were 91 students who are doing their degrees in science and other fields. The study used a modified version of FLRAS, and the study concluded that there are other factors that contribute to reading anxiety, including linguistic, cultural and curriculum factors. Besides, Zhang and Kim (2014) investigated reading anxiety among Chinese learners of Korean language. The study concluded that there are different sources of reading anxiety: fear of new topics, language structure, unfamiliar culture, reading comprehension and negative attitude towards reading in Korean language. The study also showed that reading anxiety is related to learners' grades, and this result is also obtained by Yassin and Razak (2017).

The study of Al-Shboul et al. (2013) in Jordan revealed that there are five sources of reading anxiety. The first two are related to personal factors: worry about reading effect and fear of making mistakes. However, the other three factors are related to text: unknown vocabulary, unfamiliar topic and unfamiliar culture. The same classification is found by Genc (2016), who divided reading anxiety into personal and text factors. This study also showed that ambiguity tolerance, gender and reading success are among the predictors of reading anxiety.

Another study was conducted by Subasi (2014) to investigate the sources of English reading anxiety among Turkish learners. The study revealed six sources for reading anxiety which are personal reasons, teaching procedures, teachers' manner inside the classroom during the process of teaching, test anxiety, the features of the text and the previous experience of the learners.

The variable of branch of study was taken into consideration by some researchers who investigated foreign language reading anxiety. Ismail (2015), which was conducted among secondary school female students in UAE, showed that there is a significant difference in reading anxiety between students of science and students of arts, in favor of science students. He also added that vocabulary and grammatical knowledge are sources of reading anxiety.

Moreover, the variable of level of study and gender were taken into consideration by some researcher who investigated foreign language reading anxiety. For example, Zhao (2009) investigated reading anxiety among learners of Chinese in the US. The study concluded that unfamiliar topic, unfamiliar script and worry about the effects of reading are the main sources of reading anxiety. The study also showed that intermediate students experience a higher level of reading anxiety than elementary students. Moreover, the study of Zhou (2017) investigated reading anxiety among learners of Chinese students in the US, and the findings showed that the 
major sources of reading anxiety are comprehension worries, unknown pronunciation, unfamiliar topics, and uncomfortability to read aloud.

Kilinc and Yenen (2016) among middle school in Turkey showed that that students' reading anxiety increased as they moved from one class to another. Recently, Al-Sohbani (2018) investigated reading anxiety among Yemeni secondary school students. The study showed that the students experience above moderate level of reading anxiety due to the following factors: uncertainty difficulties, pronunciation, unfamiliar culture and history, literal translation, unknown grammar and English symbols.

The level of reading anxiety might have a negative influence on the process of reading as those who experience anxiety perceive the text poorly unlike the other students (Saito et al., 1999). Moreover, the level of the study might have an effect on the process of reading as those who are advanced might experience lower level of anxiety than the beginners (Ipek, 2004; Liu, 2006). In contrast, some researchers argued that anxiety might have a positive influence on students since such feelings motivate the students to spend more time on reading to avoid losing their self-confidence and to improve their level and academic achievement (Horwitz et al., 1986; MacIntyre \& Gardner, 1989; Young, 1991; Sellers, 2000; Razak, Yassin, \& Maasum, 2017).

To sum up, reading anxiety is a distinguished phenomenon and it has different factors that contribute to raising its level. These factors are various but generally they are related to students, language and text, and unfamiliar cultural elements.

\section{Method}

\subsection{Aims of the study}

The current study aims to answer the following questions:

1) What is the level of foreign language reading anxiety among Yemeni students in Malaysian universities?

2) What are the sources of foreign language reading anxiety among Yemeni students in Malaysian universities?

3) Are there statistically significant differences in the means of responses of Yemeni students in Malaysian universities to the items of the questionnaire according to the variable 'Level of study' (Bachelor, Master and $\mathrm{PhD})$ ?

\subsection{Research Design}

The current study is quantitative in nature. It adopted the Foreign Language Reading Anxiety Scale developed by (Saito et al., 1999). The questionnaire was distributed to Yemeni international students in Malaysia in order to identify the level of reading anxiety and to identify if there is a significant difference in the means of students' responses according to variable of level of study (bachelor, Master and $\mathrm{PhD}$ ).

\subsection{Participants}

The sample of the current study was selected from undergraduate, Master and $\mathrm{PhD}$ Yemeni students studying in Malaysian universities. The sample includes 100 students: 30 undergraduate students, 28 Master students, and 42 PhD students.

\subsection{Instrument}

To collect the study data, the researchers adopted the Foreign Language Reading Anxiety Scale (FLRAS). FLRAS is a self-reported scale developed by Saito et al. (1999) to identify students' foreign language reading anxiety, students' perceptions of the various aspects of reading, and relative difficulty of reading compared to the difficulty of other language skills. The questionnaire included (20) items scored on a five-point Likert scale ranging from strongly agree to strongly disagree. As the number of items of FLRAS is (20), the possible range of the total score is 20 to 100, and the higher score, the more anxiety students had while reading in English and vice versa.

\subsection{Procedures}

The FLRAS was carried out in an online survey and it was distributed to the Yemeni students in Malaysian universities through the social networks Facebook and WhatsApp and Yemeni students from different Malaysian universities were requested to respond to the items of the scale.

\subsection{Data Analysis}

The data collected via the questionnaire were computed and analyzed using the Statistical Package of Social Sciences (SPSS) for Windows (version 17.0). As the items of the questionnaire are rated on a five-point Likert scale ranging from five points for strongly agree to one point for strongly disagree. However, the scores of the 
positive items were scored from one point for strongly agree to five points for strongly disagree, which are items number 12, 13, 14 and 18. For each item, the descriptive statistics (means, standard deviations, percentages, frequencies and their percentages) are calculated in order to measure the level of reading anxiety of Yemeni students in Malaysian universities. The researchers also used one-way ANOVA to identify whether there are statistically significant differences in the means of responses of Yemeni students in Malaysian universities for the items of the questionnaire according to the variable 'Level of study'.

\section{Results}

As indicated earlier, the current study mainly aims at investigating foreign language reading anxiety among Yemeni students in the Malaysian institutes in terms of the level and sources of reading anxiety. The results and discussion of the study are reported in the light of the study questions.

\subsection{Research Question One}

What is the level of foreign language reading anxiety among Yemeni students in Malaysian universities?

To present and discuss the results of responses to the items of the questionnaire, the researchers used three levels to describe foreign language reading anxiety of Yemeni university students in Malaysian institutes: (44 and lower) means lower level of anxiety, (45-67) means mid-level of anxiety, and (68 and above) means higher level of anxiety. High score indicates a high level of foreign language reading anxiety and lower score indicates lower level of foreign language reading anxiety.

For the first question, the researchers calculated the means, standard deviations, percentages, and frequency percentages for each item of the questionnaire. As there is no significant difference in the means of responses of the three groups to the items of the questionnaire, the researchers calculated these values for all respondents as one group. If there were significant differences in the means of responses of the three groups, it was better to find the means, standard deviation, percentages and frequency percentages for each group separately. The means, standard deviations, percentages, and frequency percentages for each item of the questionnaire are shown below.

Table 1. Means, standard deviations, percentages and frequency percentages for each item $(\mathrm{N}=100)$

\begin{tabular}{|c|c|c|c|c|c|c|c|c|c|}
\hline \multirow[t]{2}{*}{$\mathrm{NO}$} & \multirow[t]{2}{*}{ Items } & \multicolumn{3}{|c|}{ Descriptive Data } & \multicolumn{5}{|c|}{ Frequency Percentages } \\
\hline & & $M$ & $S D$ & $\%$ & SD & $\mathrm{D}$ & $\mathrm{N}$ & A & SA \\
\hline 1 & $\begin{array}{l}\text { I get upset when I'm not sure whether I understand what I am } \\
\text { reading in English. }\end{array}$ & 3.19 & 1.16 & 63.8 & 11 & 15 & 29 & 34 & 11 \\
\hline 2 & $\begin{array}{l}\text { When reading English, I often understand the words but still } \\
\text { can't quite understand what the author is saying. }\end{array}$ & 2.93 & 1.19 & 58.6 & 13 & 26 & 25 & 27 & 9 \\
\hline 3 & $\begin{array}{l}\text { When I'm reading English, I get so confused I can't remember } \\
\text { what I'm reading. }\end{array}$ & 2.72 & 1.15 & 54.4 & 13 & 36 & 25 & 18 & 8 \\
\hline 4 & $\begin{array}{l}\text { I feel intimidated whenever I see a whole page of English in } \\
\text { front of me. }\end{array}$ & 2.42 & 1.15 & 48.4 & 26 & 27 & 32 & 9 & 6 \\
\hline 5 & $\begin{array}{l}\text { I am nervous when I am reading a passage in English when I } \\
\text { am not familiar with the topic. }\end{array}$ & 2.98 & 1.15 & 59.6 & 9 & 31 & 21 & 31 & 8 \\
\hline 6 & $\begin{array}{l}\text { I get upset whenever I encounter unknown grammar when } \\
\text { reading English. }\end{array}$ & 2.74 & 1.16 & 54.8 & 15 & 32 & 23 & 24 & 6 \\
\hline 7 & $\begin{array}{l}\text { When reading English, I get nervous and confused when I don't } \\
\text { understand every word. }\end{array}$ & 2.94 & 1.25 & 58.8 & 16 & 20 & 30 & 22 & 12 \\
\hline 8 & $\begin{array}{l}\text { It bothers me to encounter words I can't pronounce while } \\
\text { reading English. }\end{array}$ & 2.98 & 1.08 & 59.6 & 8 & 27 & 32 & 25 & 8 \\
\hline 9 & $\begin{array}{l}\text { By the time you get past the funny letters and symbols in } \\
\text { English, it's hard to remember what you're reading about. }\end{array}$ & 2.88 & 0.97 & 57.6 & 8 & 27 & 36 & 27 & 2 \\
\hline 10 & $\begin{array}{l}\text { I usually end up translating word by word when I'm reading } \\
\text { English. }\end{array}$ & 2.65 & 1.19 & 53 & 21 & 26 & 25 & 23 & 5 \\
\hline 11 & $\begin{array}{l}\text { I am worried about all the new symbols you [I] have to learn in } \\
\text { order to read English. }\end{array}$ & 2.79 & 1.13 & 55.8 & 14 & 28 & 29 & 23 & 6 \\
\hline 12 & *I enjoy reading English. & 2.41 & 1.33 & 48.2 & 32 & 28 & 18 & 11 & 11 \\
\hline 13 & *I feel confident when I am reading in English. & 2.51 & 1.18 & 50.2 & 25 & 27 & 24 & 20 & 4 \\
\hline 14 & *Once you get used to it, reading English is not so difficult. & 3.08 & 1.09 & 61.6 & 9 & 18 & 39 & 24 & 10 \\
\hline 15 & The hardest part of learning English is learning to read. & 2.73 & 1.08 & 54.6 & 13 & 31 & 31 & 20 & 5 \\
\hline 16 & $\begin{array}{l}\text { I would be happy just to learn to speak English rather than } \\
\text { having to learn to read as well. }\end{array}$ & 3.02 & 1.28 & 60.4 & 17 & 16 & 28 & 26 & 13 \\
\hline 17 & $\begin{array}{l}\text { I don't mind reading to myself, but I feel very uncomfortable } \\
\text { when I have to read English aloud. }\end{array}$ & 3.07 & 1.09 & 61.4 & 7 & 24 & 35 & 23 & 11 \\
\hline 18 & $\begin{array}{l}\text { *I am satisfied with the level of reading ability in English that I } \\
\text { have achieved so far. }\end{array}$ & 3.07 & 0.97 & 61.4 & 6 & 19 & 43 & 26 & 6 \\
\hline 19 & English culture and ideas seem very foreign to me. & 2.98 & 1.03 & 59.6 & 8 & 23 & 39 & 23 & 7 \\
\hline 20 & $\begin{array}{l}\text { You have to know so much about English history and culture in } \\
\text { order to read English. }\end{array}$ & 2.89 & 1.31 & 57.8 & 17 & 26 & 22 & 21 & 14 \\
\hline
\end{tabular}

Note. Scale: $\mathrm{SD}=$ Strongly Disagree, $\mathrm{D}=$ Disagree, $\mathrm{N}=$ Neutral, $\mathrm{A}=$ Agree, $\mathrm{SA}=$ Strongly Agree.

*negative items were reversed before scoring. 
In general, Yemeni students in the Malaysian universities experience a moderate level of foreign language reading anxiety $(M=2.85, S D=0.67 \& 57 \%)$. Table 1 shows that averages of the statements of the questionnaire ranged from 2.41 to 3.19 with corresponding percentages ranged from $48.2 \%$ to $63.8 \%$. This means that Yemeni students in Malaysian universities experienced a moderate level of foreign language reading anxiety with all the items of the scale with.

Table 2 highlights the level of foreign language reading anxiety of Yemeni students (Bachelor, Master, Doctorate) in the Malaysian universities separately.

Table 2. Level of anxiety according to the level of study

\begin{tabular}{lllll}
\hline Level & $N$ & $M$ & $\%$ & Estimation \\
\hline Master & 28 & 2.75 & 54.96 & Medium \\
Doctor & 42 & 2.82 & 56.31 & Medium \\
Bachelor & 30 & 2.99 & 59.8 & Medium \\
\hline
\end{tabular}

Table 2 shows that all Yemeni students in Malaysian universities regardless of their level of education, Bachelor's, Master's and $\mathrm{PhD}$ experience a moderate level of foreign language reading anxiety. The table also shows that the students of bachelor's degree experience the highest level of foreign language reading anxiety followed by students of $\mathrm{PhD}$ and students of master degree consecutively. However, there is not significant differences among all the groups.

\subsection{Research Question Two}

What are the sources of foreign language reading anxiety among Yemeni students in Malaysian universities?

Table 1 also shows the frequency percentages of responses to the items of the questionnaire. From this analysis, one can identify the sources of foreign language reading anxiety from the perspective of Yemeni students in Malaysian universities.

The highest rating was given to item 1 , which received a mean of 3.19 and a percentage of $63.8 \%$. This indicates that inability to understand a reading text can raise the level of foreign language reading anxiety. Table 1 also indicates that the mean scores of the level of foreign language reading anxiety that Yemeni students in the Malaysian universities experience are above 3.00 point in four other items. These items are 14, 17, 18, and 16. The means of these items are 3.08, 3.07, 3.07, and 3.06 with corresponding percentages 61.6, 61.4, 61.4, and 60.4 respectively. This highlight the importance of reading more in the target language, using the appropriate mode of reading, the feeling of satisfaction with the level that one achieves in the target language, and developing speaking skill to reduce the level of foreign language reading anxiety. The lowest rating was given to statement 12, I enjoy reading English, which received a mean of 2.41 and a percentage of $48.2 \%$ as Table 1 indicates.

An important point which supports that the students experience foreign language reading anxiety is the percentage of the neutral choice. A lot of students have ticked the neutral choice as they are not sure about their feelings and this is noticed in almost all the items.

\subsection{Research Question Three}

Are there statistically significant differences in the means of responses of Yemeni students in Malaysian universities to the items of the questionnaire according to the variable 'Level of study' (Bachelor, Master and $\mathrm{PhD})$ ?

To answer the third question, i.e., to identify whether there are statistically significant differences in the mean scores of the responses of Yemeni students in Malaysian universities according to the variable 'Level of the study' (bachelor, master, doctorate), the researchers used one-way ANOVA. The results of the one-way ANOVA are shown in Table 3.

Table 3. Results of One-way ANOVA Analysis for the Variable 'Level of Study'

\begin{tabular}{llllll}
\hline & Sum of Squares & $d f$ & Mean Square & $F$ & Sig. \\
\hline Between Groups & 0.928 & 2 & 0.464 & 1.050 & 0.354 \\
Within Groups & 42.887 & 97 & 0.442 & & \\
Total & 43.815 & 99 & & & \\
\hline
\end{tabular}


The analysis in Table 3 shows that there are no significant statistical differences in the responses mean scores of the students according to the variable 'Level of the study' (bachelor, Master, $\mathrm{PhD}$ ) at the 0.05 level of significance. The $F$-value was 1.050 , which showed that no significant differences at $\alpha=0.05$ since the $p$-value $>$ $0.05(p=0.354)$. This means that Yemeni students in Malaysian universities perceive the level of FLRA in the same way regardless their level of study.

\section{Discussion}

The aim of the first question is to investigate the level of reading anxiety among Yemeni international students in the Malaysian universities. The result of the analysis showed that the level of anxiety is moderate among all the students regardless of their level of education, Bachelor's, Master's and PhD. Previous studies, such as Joo and Damron (2015), argued that the level of education reduces the level of reading anxiety. However, the result of this study opposes this opinion as the analysis shows that the students cannot overcome reading anxiety with passage of time. This might be attributed to the fact that the students read materials in English language. This makes anxiety feeling a part of the learning process which is in line with the study of Grabe and Stoller (2001).

Also, the result of the study is different from that of previous studies such as Al-Shboul et al. (2013), because these studies investigated reading anxiety among EFL students in their home country. However, the current study investigated reading anxiety among Yemeni students in the host country in which the main language of instruction is English language. This gives a new direction for the investigation of reading anxiety which is the environment. Thus, the moderate level of reading anxiety across the three group might be attributed to the environment. Malaysian learning environment requires reading in English all the time which makes this factor have a great influence in reducing reading anxiety.

However, the inability to get rid of reading anxiety indicates that reading anxiety is related to the process of foreign language learning. Although the students could alleviate the level of anxiety, it is difficult to get rid of reading anxiety and keep it at the lower level among all the learners. This might be attributed to the idea that students have to read new materials whatever their level. This makes novelty affect a part of reading anxiety even if the students have advanced level in English language as stated by Yassin and Razak (2017). The idea of novelty effect can be understood from the investigation of reading anxiety difference among the students in terms of their level of education, namely Bachelor's, Master's and $\mathrm{PhD}$. The results showed that there is not a significant difference among the three groups. This might be attributed to the fact that during the study period, the students come across different reading materials which makes them obliged to not only decoding words, but also understand different text factors such as unknown vocabulary and unfamiliar topics. This makes it difficult for the students to overcome the feeling of anxiety, and this result is in line with Genç (2016).

The major sources of reading anxiety according to the responses of the students include uncertainty, English words pronunciation, unfamiliar topic, unknown vocabulary, reading aloud, word by word translation, unfamiliar English culture and history, unfamiliar grammar, English letters and symbols. This puts weakness in reading skills as a major factor in reading anxiety. Although the students still experience reading anxiety, they know that reading becomes easier once they become used to it as stated in item 14. This supports the idea that students need to improve their reading skills both bottom-up — related to the text—and top-down — related to the reader. Therefore, reading skills might play a major role in reading anxiety, because reading skills helps students to link between different parts of the text, and students can deal even with difficult passages if they have mastered reading skills.

Previous studies, such as Joo and Damron (2015) indicated that the level of education played a significant role in the level of students' reading anxiety; students of low level of education feel significantly more anxious about reading than those of high level. However, the result of this study opposes this opinion as the analysis shows that the students can alleviate, but not overcome, reading anxiety with passage of time. This might be attributed to the fact that the students read materials in English language constantly. This makes anxiety feeling a part of the learning process.

Reading anxiety is a normal feeling accompanying student and it is difficult to overcome such feeling, which is clear from the results of Master's and PhD students. This opposes the findings of Satio and Samimy (1996) and Zhao, Guo and Dynia (2013) that the level of anxiety decreases among advanced learners, because these studies were conducted on students of Japanese language in the United States. However, this study is conducted among Yemeni students in Malaysia in which the learning environment is totally in English language. This might explain the different in the findings of both studies.

Regarding the significant differences in the responses of the sample according to the level of study, the results of the current study are not in line with those of Zhao (2009), which indicated that there was a significant course 
level effect on the level of foreign language reading anxiety with intermediate students having a significantly higher level of foreign language reading anxiety than elementary students. The results of this study are not also in line with those of Zhou (2017), which indicated that 100- and 400-level students experienced higher levels of reading anxiety compared to 200- and 300-level students. Moreover, comparing the current study with Al-Sohbani (2018), which indicated that Yemeni secondary school students in Yemen experience above moderate level of reading anxiety $(\mathrm{M}=3.10$, percentage $62 \%)$; the researchers can state that the level of study and the environment of learning can play an important role in lower the level of foreign language reading anxiety among learners. This gives a new direction for the investigation of reading anxiety which is the environment. Thus, the moderate level of reading anxiety across the three group might be attributed to the environment. Although students are studying different majors, Malaysian learning environment requires reading in English all the time, which makes this factor have a great influence in alleviating reading anxiety.

To put it simply, although previous studies showed that learning in a new environment is source of learning anxiety and academic challenges (Al-Zubaidi \& Rechards, 2009; Mustapha, Rahman, \& Yunus, 2010; Alavi \& Mansor, 2011; Talebloo \& Basri, 2015), this study proved that learning in an environment where the language of instruction is English helps to reduce the level of reading anxiety.

\section{Conclusion}

This study aimed at identifying the level and sources of foreign language reading anxiety among Yemeni students in Malaysian universities. The results showed that Yemeni students in the three levels of education-Bachelor's, master's and $\mathrm{PhD}$ - in Malaysian university experience a moderate level of foreign language reading anxiety, and there are no statistically significant differences between the three groups. However, study showed that the major sources of reading anxiety include uncertainty, English words pronunciation, unfamiliar topic, unknown vocabulary, reading aloud, word by word translation, unfamiliar English culture and history, unfamiliar grammar, English letters and symbols.

This study concludes that another factor needs to be taken into consideration when studying foreign language reading anxiety, which is the learning environment. It is concluded that English learning environment, like Malaysia, can help students to reduce their foreign language reading anxiety. However, foreign language reading anxiety is a normal learning feeling due to the new materials that the students have to read from time to time to get knowledge.

\section{References}

Akkakoson, S. (2016). Speaking Anxiety in English Conversation Classrooms among Thai Students. Malaysian Journal of Learning and Instruction, 13(1), 63-82. https://doi.org/10.32890/mjli2016.13.1.4

Alavi, M., \& Mansor, S. M. S. (2011). Categories of problems among international students in Universiti Teknologi Malaysia. Procedia-Social and Behavioral Sciences, 30, 1581-1587. https://doi.org/10.1016/j.sbspro.2011.10.307

Ali, T. T., \& Fei, W. F. (2016). Foreign Language Classroom Anxiety among Iraqi Students and its Relation with Gender and Achievement. International Journal of Applied Linguistics and English Literature, 6(1), 305-310. https://doi.org/10.7575/aiac.ijalel.v.6n.1p.305

Al-Shboul, M. M., Ahmad, I. S., Nordin, M. S., \& Rahman, Z. A. (2013). Foreign language reading anxiety in a Jordanian EFL context: A qualitative study. English Language Teaching, 6(6), 38. https://doi.org/10.5539/elt.v6n6p38

Al-Sohbani, Y. A. (2018). Foreign Language Reading Anxiety among Yemeni Secondary School Students. International Journal of English Language \& Translation Studies, 6(1), 57-65.

Al-Zubaidi, K., \& Richards, C. (2010). Arab postgraduate students in Malaysia: Identifying and overcoming the cultural and language barriers. Arab World English Journal, 1(1), 107-129. https://doi.org/10.24093/awej/vol1 no1.5

Genç, G. (2016). Can ambiguity tolerance, success in reading, and gender predict the foreign language reading anxiety? Journal of Language and Linguistic Studies, 12(2), 135-151.

Grabe, W., \& Stoller, F. L. (2001). Reading for Academic Purposes: Guidelines for the ESL/EFL Teacher. In M. Celce-Murcia (Ed.), Teaching English as a Second or Foreign Language (3rd ed., pp. 187-203). Boston: Heinle \& Heinle.

Horwitz, E. K., Horwitz, M. B., \& Cope, J. (1986). Foreign language classroom anxiety. The Modern Language Journal, 70(2), 125-132. https://doi.org/10.1111/j.1540-4781.1986.tb05256.x 
Ipek, H. (2004). Foreign language reading anxiety: Proficiency and gender. The International Journal of Learning, 16(8), 293-300.

Ismail, S. A. (2015). Secondary School Students Reading Anxiety in a Second Language. English Language Teaching, 8(11), 28-41. https://doi.org/10.5539/elt.v8n11p28

Joo, K. Y., \& Damron, J. (2015). Foreign language reading anxiety: Korean as a foreign language in the United States. Journal of the National Council of Less Commonly Taught Languages, 17, 23-55.

Kilinc, H. H., \& Emin Tamer Yenen, E. T. (2016). Investigation of students' reading anxiety with regards to some variables. International Journal of Higher Education, 5(1), 111-118. https://doi.org/10.5430/ijhe.v5n1p111

Kuru-Gonen, I. (2005). The Sources of Foreign Language Reading Anxiety of Students in a Turkish EFL Context. Master Thesis, Anadolu Universitesi Egitim Bilimleri Enstitusu.

Kuru-Gonen, I. (2007). L2 Reading Anxiety; Exploring the Phenomenon. In B.-W. K. (Ed.), JALT2006 KITAKYUSHU Community, Identity, Motivation. Tokyo: JALT.

Kuru-Gonen, I. (2009). The Sources of Foreign Language Reading Anxiety of Students in a Turkish EFL Context. Paper presented at the 5th WSEAS/IASME International Conference on EDUCATIONAL TECHNOLOGIES (EDUTE’ 09), Spain.

Liu, M. (2006). Anxiety in Chinese EFL students at different proficiency levels. System, 34(3), 301-316. https://doi.org/10.1016/j.system.2006.04.004

Liu, M., \& Huang, W. (2011). An Exploration of Foreign Language Anxiety and English Motivation. Education Research International, 1-8. https://doi.org/10.1155/2011/493167

MacIntyre, P. D., \& Gardner, R. C. (1989). Anxiety and second language learning: Toward a theoretical clarification. Language Learning, 39(2), 251-275. https://doi.org/10.1111/j.1467-1770.1989.tb00423.x

MacIntyre, P. D., \& Gardner, R. C. (1994). The subtle effects of language anxiety on cognitive processing in the second language. Language Learning, 44(2), 283-305. https://doi.org/10.1111/j.1467-1770.1994.tb01103.x

Mustapha, S. M., Rahman, N. S. N. A., \& Yunus, M. M. (2010). Perceptions towards classroom participation: A Case Study of Malaysian Undergraduate Students. Procedia-Social and Behavioral Sciences, 7, 113-121. https://doi.org/10.1016/j.sbspro.2010.10.017

Olivares-Cuhat, G. (2010). Relative Importance of Learning Variables on L2 Performance. Linguistik Online, 43(3), 99-116.

Pappamihiel, N. E. (2002). English as a second language students and English language anxiety: Issues in the mainstream classroom. Research in the Teaching of English, 327-355.

Rajaba, A., Zakariab, W., Rahmanc, H., Hosnid, D., \& Hassanie, S. (2012). Reading Anxiety among Second Language Learners. Procedia - Social and Behavioral Sciences, 66, 362-369. https://doi.org/10.1016/j.sbspro.2012.11.279

Razak, N. A., Yassin, A. A., \& Mohamad, T. N. R. B. T. (2017). Effect of Foreign Language Anxiety on Gender and Academic Achievement among Yemeni University EFL Students. English Language Teaching, 10(2), 73. https://doi.org/10.5539/elt.v10n2p73

Sahranavard, M., \& Hassan, S. (2015). Investigation of Construct Validity of State Anxiety Inventory among Iranian 8th Grade Students. Asian Journal of Applied Sciences, 8(1), 63-70. https://doi.org/10.3923/ajaps.2015.63.70

Saito, Y., Garza, T. J., \& Horwitz, E. K. (1999). Foreign language reading anxiety. The Modern Language Journal, 83(2), 202-218. https://doi.org/10.1111/0026-7902.00016

Sellers, V. D. (2000). Anxiety and reading comprehension in Spanish as a foreign language. Foreign Language Annals, 33(5), 512-521. https://doi.org/10.1111/j.1944-9720.2000.tb01995.x

Subasi, G. (2014). Foreign language reading anxiety: Does it really exist? Educational Research and Reviews, 9(24), 1360.

Talebloo, B., \& Basri, R. (2015). Multicultural benefits and challenges for international students during period of their study: Case study in Malaysia. Journal of Educational, Health and Community Psychology, 4(1), 3647. 
Wei, J., \& Yodkamlue, B. (2012). The Chinese Bouyei college students' classroom anxiety in foreign language learning: A survey study. International Journal of English Linguistics, 2(2), 75. https://doi.org/10.5539/ijel.v2n2p75

Wu, H.-J. (2011). Anxiety and Reading Comprehension Performance in English as a Foreign Language. Asian EFL Journal, 13(2), 273-307.

Yassin, A. A., \& Razak, N. A. (2017). Investigating the Relationship Between Foreign Language Anxiety in the Four Skills and Year of Study Among Yemeni University EFL Learners3L. Language, Linguistics, Literature, 23(3). https://doi.org/10.17576/3L-2017-2303-11

Yassin, A. A., \& Razak, N. A. (2018). Investigating Foreign Language Learning Anxiety among Yemeni University EFL Learners: A Theoretical Framework Development. English Language Teaching, 11(10), 38-51. https://doi.org/10.5539/elt.v11n10p38

Young, D. J. (1991). Creating a low-anxiety classroom environment: What does language anxiety research suggest? The Modern Language Journal, 75, 426-437. https://doi.org/10.1111/j.1540-4781.1991.tb05378.x

Zhang, H., \& Kim, Y. (2014) Foreign language reading anxiety: Chinese learners of Korean. Studies in Linguistics, 32, 21-45.

Zhang, R., \& Zhong, J. (2012). The hindrance of doubt: Causes of language anxiety. International Journal of English Linguistics, 2(3), 27. https://doi.org/10.5539/ijel.v2n3p27

Zhao, A. (2009). Foreign language reading anxiety: Investigating English-speaking university students learning Chinese as a foreign language in the United States. Doctoral Dissertation. Florida State University, College of Education, the United States.

Zhao, A., Guo, Y., \& Dynia, J. (2013). Foreign language reading anxiety: Chinese as a foreign language in the United States. The Modern Language Journal, 97(3), 764-778. https://doi.org/10.1111/j.1540-4781.2013.12032.x

Zhou, J. (2017). Foreign language reading anxiety in a Chinese as a foreign language context. Reading in a Foreign Language, 29(1), 155-173.

\section{Copyrights}

Copyright for this article is retained by the author, with first publication rights granted to the journal.

This is an open-access article distributed under the terms and conditions of the Creative Commons Attribution license (http://creativecommons.org/licenses/by/4.0/). 